\begin{tabular}{|l|l|l||}
\hline \multicolumn{2}{|c|}{ PublisherInfo } \\
\hline \hline PublisherName & $:$ & BioMed Central \\
\hline \hline PublisherLocation & $:$ & London \\
\hline \hline PublisherImprintName & $:$ & BioMed Central \\
\hline \hline
\end{tabular}

\title{
RhoC oncogene and inflammatory breast cancer
}

\begin{tabular}{|l|l|l||}
\hline \multicolumn{2}{|c|}{ ArticleInfo } \\
\hline \hline ArticleID & $:$ & 3740 \\
\hline \hline ArticleDOI & $:$ & $10.1186 /$ bcr-2000-66703 \\
\hline \hline ArticleCitationID & $:$ & 66703 \\
\hline \hline ArticleSequenceNumber & $:$ & 106 \\
\hline \hline ArticleCategory & $:$ & Paper Report \\
\hline \hline ArticleFirstPage & $:$ & 1 \\
\hline \hline ArticleLastPage & $:$ & 4 \\
\hline \hline & & RegistrationDate : 2000-12-6 \\
\hline ArticleHistory & $:$ & OnlineDate \\
\hline \hline ArticleCopyright & $:$ & Current Science Ltd2000-12-6 \\
\hline \hline ArticleGrants & $:$ & \\
\hline \hline ArticleContext & $:$ & 1305822 \\
\hline \hline
\end{tabular}


Aff1 Breast Center, Baylor College of Medicine, Texas, USA

\section{Keywords}

HME, inflammatory breast cancer, oncogene, overexpression, RhoC GTPase (ARHC)

\section{Introduction}

RhoC is a member of the Ras superfamily of small GTPase signal transduction proteins. RhoC regulates remodeling of the actin cytoskeleton and cell motility.IBC has an extremely aggressive and rapid clinical course, such that at diagnosis, it is nearly always axillary lymph node positive (with distant metastases in a third of the cases). These studies implicate RhoC, its modulation of the actin cytoskeleton, and related increases in cell motility in the aggressive phenotype of IBC.

\section{Aims}

To correlate overexpression of RhoC GTPase with IBC by characterizing the biological phenotype of RhoC overexpression in an HME model system.

\section{Comments}

Inflammatory breast cancer (IBC) is an infrequent but highly aggressive form of invasive breast cancer. RhoC has been shown to be overexpressed in $90 \%$ of IBC lesions. This report demonstrates that $\mathrm{RhoC}$ overexpression in otherwise 'normal' appearing immortalized human mammary epithelial cell lines (HME-RhoCs) induces anchorage independence, high cell motility, invasiveness, and a pattern of actin stress fibers approximating those seen in IBC cell lines. The HME-RhoC lines also demonstrated a $25 \%$ tumor take in nude mice in vivo. This report provides convincing evidence that the HME-RhoC lines recapitulate elements of the IBC phenotype, but does not attempt to extend these results to the far more abundant noninflammatory classes of invasive breast cancer. Recent cDNA array analyses (see Additional information) have also implicated overexpression of $\mathrm{RhoC}$ in a melanoma model of metastasis. 


\section{Methods}

A RhoC expression construct was transfected into a human papilloma virus (HPV) E6/E7 gene immortalized HME cell line. Co-transfer of RhoC pFLAG-CMV-4 was achieved using PTP-2000 hygromycin vectors and the transfectants were cultured on a hygromycin medium. Stable transfectants were selected using RT-PCR and western blot. Cell growth rates were assessed by monolayer cell culture and anchorage-independent cell culture in soft agar. A cell motility assay was performed as was a Matrigel assay to assess cell invasiveness. Actin stress fibres were observed by microscopic examination of cells labeled with rhodamine-tagged phallotoxin. In vivo tumor formation was assessed by implantation into mammary fat pads of female nude mice.

\section{Results}

HME-RhoC lines showed unchanged monolayer growth rates relative to controls, but acquired anchorage independent colony formation to varying degrees. The polyclonal HME-RhoC line formed soft-agar colonies at $63 \%$ of the level of the SUM149 IBC (control) cell line. Individual HME-RhoC clones and the polyclonal HME-RhoC lines were as invasive as the SUM149 IBC cell line in Matrigel assays, showing five- to sevenfold increases relative to control HMEs. HME-RhoC lines showed increased random motility (70-80\% motile cells) relative to both HMEs (10\% motile cells), and SUM149 IBC (50\% motile cells) cell lines. Focal adhesions and actin stress fibers were absent in HME controls, but comparable in HME-RhoC and SUM143 IBC cell lines. HME-RhoC cells implanted into the mammary fat pad of female nude mice showed a tumor take of 5 out of 20, relative to 0 out of 20 for control HMEs and 17 out of 20 for the SUM149 IBC cell line.

\section{Discussion}

HPV E6/E7 transformation inactivates the p53 and retinoblastoma genes and immortalizes HMEs, but does not confer anchorage independence or a malignant phenotype. The HME-RhoC lines took on a number of phenotypic attributes of the SUM149 IBC cell line relative to control HME lines. The authors conclude that the HME-RhoC lines recapitulate aspects of the SUM149 IBC cell line phenotype. The authors suggest that differences in the efficiency of tumor formation in vivoare likely explained by as yet uncharacterized genetic changes in the SUM149 cell line relative to the HME-RhoC lines. Future studies will focus on the role of the RhoC pathway in the invasive phenotype of IBC. Agents that interfere with RhoC activity are suggested as new therapeutic interventions for this disorder.

\section{Additional information}


Clarke EA, Golub TR, Lander ES, Hynes RO: Genomic analysis of metastasis reveals an essential role for RhoC. Nature 2000, 406:532-535.

\section{Further reading.}

Van Golen KL, Davies S, Wu ZF, Wang Y, Bucana CD, Root H, Chandrasekharappa S, Strawderman M, Eihier SP, Merajver SD: A novel putative low-affinity insulin-like growth factor-binding protein, LIBC (lost in inflammatory breast cancer), and RhoC GTPase correlate with the inflammatory breast cancer phenotype. Clin Cancer Res 1999, 5:2511-2519.

See also the recent review article:

Kleer CG, van Golen KL, Merajver SD: Molecular biology of breast cancer metastasis:

Inflammatory breast cancer: clinical syndrome and molecular determinants. Breast Cancer Res 2000, 2:423-429 (abstract)

\section{References}

1. Golen KL, Wu Z-F, Qiao XT, Bao LW, Merajver SD: RhoC GTPase, a novel transforming oncogene for human mammary epithelial cells that partially recapitulates the inflammatory breast cancer phenotype. Cancer Res. 2000, 60: 5832-5838.

This PDF file was created after publication. 